\title{
HEART RATES AT SUBMAXIMAL RELATIVE WORKLOADS IN SUBJECTS OF HIGH AND MEDIUM FITNESS
}

\author{
R. T. WITHERS* and R. W. HASLAM
}

Department of Physical Education, University of Maryland, College Park, Maryland, 20742

\begin{abstract}
Eight subjects of high fitness $\left(\mathrm{VO}_{2} \max -56.9 \mathrm{ml} / \mathrm{kg} \mathrm{x} \mathrm{min}\right)$ and eight subjects of medium fitness $\left(\mathrm{VO}_{2} \max =43.4\right.$ $\mathrm{ml} / \mathrm{kg} \times \mathrm{min}$ ) pedalled a bicycle ergometer for 6 minutes at workloads which elicited $70 \%, 80 \%$ and $90 \%$ of their individual $\mathrm{VO}_{2}$ max. Heart rates were recorded during the last 30 seconds of each workload.

The data were analysed by a 2 (fitness levels) $\times 3$ (workloads) analysis of variance factorial design. Although the high fitness group recorded a lower mean heart rate for the 3 workloads $(155$ beats $/ \mathrm{min}$ ) than the medium fitness group ( $161 \mathrm{beats} / \mathrm{min})$, there was no overall statistically significant difference between the 2 fitness levels. The difference was most marked at the highest workload where a statistically significant $(p<.05)$ interaction occurred between workload and fitness level. A completely randomised design analysis of variance indicated that the high fitness group attained their $\mathrm{VO}_{2} \max$ at a statistically significant lower heart rate $(173$ beats $/ \mathrm{min})$ than the medium fitness group (182 beats $/ \mathrm{min}$ ).
\end{abstract}

\section{Introduction}

The literaiure contains numerous reference to the fact that trained persons have lower heart rates than untrained subjects at absolute submaximal workloads. This is assumed, reasonably, to be due to the greater stroke volume of the former. However, little information has been published regarding the existence of any differences at submaximal workloads. Thus the purpose of this study was to compare statistically the heart rates of high and medium fitness groups when the subjects experienced submaximal relative workloads of $70 \%, 80 \%$, and $90 \%$ of their $\mathrm{VO}_{2}$ max on the bicycle ergometer. $\mathrm{A}$ secondary purpose was to effect a between-fitness level comparison of the heart rate at which $\mathrm{VO}_{2}$ max was attained.

\section{Method}

The high fitness group comprised members of the Washington D.C. roadrunner's club whereas the medium fitness group consisted of graduate Physical Education students. Initially all subjects were tested for $\mathrm{VO}_{2}$ max by the indirect open circuit method of calorimetry. The outlet of a triple "J" high velocity respiratory valve was connected to a hans Rudolph five-way valve by means of a metre length of $3.8 \mathrm{~cm}$ internal diameter plastic tubing. This enabled expired air to be collected in 1501 Douglas bags. A Collins motor blower aspirated the expired air through a Singer dry gas meter. Expired gas samples were analysed for $\mathrm{O}_{2}$ and $\mathrm{CO}_{2}$ by paramagnetic and infrared gas analysers respectively. A computer programme was used to determine the $\mathrm{VO}_{2}$ values (9).

The first visit to the laboratory consisted of continuous workloads of 150 Joules and 210 Joules (900 and $1260 \mathrm{kgm} / \mathrm{min}$ ) for 6 and $5 \mathrm{~min}$ respectively. The Monark bicycle ergometer was equipped with toeclips and pedalled at a cadence of $60 \mathrm{rpm}$. Heart rate was recorded by means of a Beckman Type RS Dynograph for the last $\mathbf{3 0}$ seconds of each workload in this experiment using a CM5 electrode placement. Expired air was collected during the last minute of each workload period and $\mathrm{VO}_{2}$ max was estimated from the Åstrand-Rhyming nomogram (1). The final workload for the first visit was an initial $2 \frac{1}{2} \mathrm{~min}$ warmup at 150 Joules $(900 \mathrm{kgm} / \mathrm{min})$ followed by a $2 \frac{1}{2}$ min workload which was estimated to require an oxygen uptake approximately $15 \%$ greater than the predicted value. Expired air was collected during the last $\mathbf{3 0}$ seconds of the workload. This was the pattern for subsequent visits to the laboratory. Sometimes it was necessary to collect air from $1 \frac{1}{2}-2$ or $13 / 4-2 \frac{1}{4}$ min of exercise. Asstrand and Saltin (2) have shown that the heavier the workload then the faster the increase in $\mathrm{VO}_{2}$. Thus provided there is an adequate warmup period the work time at these high workloads can be shorter when compared with lower workloads. Maximum oxygen uptake was decreed to have been attained at that point at which an increase in workload of 30 Joules (180 $\mathrm{kgm} / \mathrm{min}$ ) elicited a rise in $\mathrm{VO}_{2}$ of $150 \mathrm{ml} / \mathrm{min}$ or less. The reliability coefficient for $\mathrm{VO}_{2} \max$ in $\mathrm{ml} / \mathrm{kg} \times \mathrm{min}$ for the 16 subjects was .950 .

The inclusion of submaximal loads for each subject meant that it was possible to construct individual graphs of oxygen uptake versus workload. These graphs were then interpolated to determine the workloads which were necessary to elicit $70 \%, 80 \%$, and $90 \%$ of each subject's $\mathrm{VO}_{2}$ max. The order of performance of the 3

* Present address: School of Social Sciences, The Flinders University of South Australia, Bedford Park, South Australia, 5042. 
submaximal workloads was then assigned randomly to each subject in the 2 fitness levels. Each of these workloads was of $6 \mathrm{~min}$ duration and preceded by a $2 \frac{1}{2} \mathrm{~min}$ warmup at $60 \%$ of $\mathrm{VO}_{2}$ max.

\section{Results}

The descriptive statistics for the 2 fitness levels are contained in Table I. The $\mathrm{VO}_{2}$ max means for the high and medium fitness groups were 56.9 and $43.4 \mathrm{ml} / \mathrm{kg} x$ min respectively.

The exercise heart rate was based on the last 30 seconds of each workload. The data was analysed by a 2 (fitness levels) $\times 3$ (workloads) analysis of variance factorial design with repeated measures on workloads. Table II is a summary of the analysis. The .05 probability level was used for all tests of statistical significance. The tests for the 3 null hypotheses may be summarised as follows:

1) A test of " $B$ " or fitness levels effect was conducted with 1 and 14 degrees of freedom. The null hypothesis was found to be tenable. The mean heart rates, when summed across all three workloads, were 161.4 and 155.2 beats $/ \mathrm{min}$ for the medium and high fitness groups respectively. It was these two means which were found not to differ statistically.

2) The test for " $A$ " or workloads effect was evaluated with 2 and 28 degrees of freedom. The three means for the combined fitness levels were 147.9, 156.9, and 170.4 beats $/ \mathrm{min}$ when working at $70 \%, 80 \%$, and $90 \%$ of $\mathrm{VO}_{2}$ max respectively. The null hypothesis was rejected and a Newman-Keuls post-hoc test revealed that all three heart rate means differed from each other at the .05 level.

3) The $A B$ interaction (workloads $x$ fitness levels) test with 2 and 28 degrees of freedom revealed a statistically significant $F$ ratio of 3.47. A NewmanKeuls post-hoc test indicated that interaction occurred at the $90 \% \mathrm{VO}_{2}$ max workload. The interaction was due to the fact that there was a greater difference in heart rate between the 2 fitness levels at this highest workload than at either of the 2 lower workloads. This is well demonstrated in Figure 1.

\section{Table I}

Descriptive Statistics for Age, Height, Weight, and Maximum Oxygen Uptake of the Medium and High Fitness Groups

\begin{tabular}{|c|c|c|c|c|}
\hline \multirow[b]{2}{*}{ Age in Years } & \multicolumn{2}{|c|}{$\begin{array}{l}\text { Medium Fitness } \\
(n=8)\end{array}$} & \multicolumn{2}{|c|}{$\begin{array}{l}\text { High fitness } \\
(n=8)\end{array}$} \\
\hline & $\begin{array}{r}\text { Mean } \\
26.0\end{array}$ & $\begin{array}{l}\text { S.D. } \\
1.8\end{array}$ & $\begin{array}{r}\text { Mean } \\
24.6\end{array}$ & $\begin{array}{l}\text { S.D. } \\
4.6\end{array}$ \\
\hline Height in $\mathrm{Cm}$ & 177.3 & 5.3 & 178.0 & 4.3 \\
\hline Weight in $\mathrm{Kg}$ & 76.5 & .1 & 65.4 & 4.9 \\
\hline $\mathrm{VO}_{2} \max \mathrm{L} / \mathrm{Min}$ & 3.2 & .2 & 3.7 & .3 \\
\hline$\dot{\mathrm{VO}}_{2} \max \mathrm{Mls} / \mathrm{kg} \times \min$ & 43.4 & 3.0 & 56.9 & 3.2 \\
\hline
\end{tabular}

Table II

Analysis of Variance for Heart Rates

$\begin{array}{llll}\text { Source } & \text { D.F. S.S. }\end{array}$

Between Subjects

Fitness Levels (B) $\quad 1 \quad 462.52 \quad 462.52$

Subjects (S)

$14 \quad 3302.45$

235.89

Within Subjects

Workloads (A)

Interaction (AB)

Error (AS)

3961.50

155.17

1980.75

77.59

$88.50^{a}$

$3.47^{a}$

Total

47

8508.31

a Significant at the .05 level

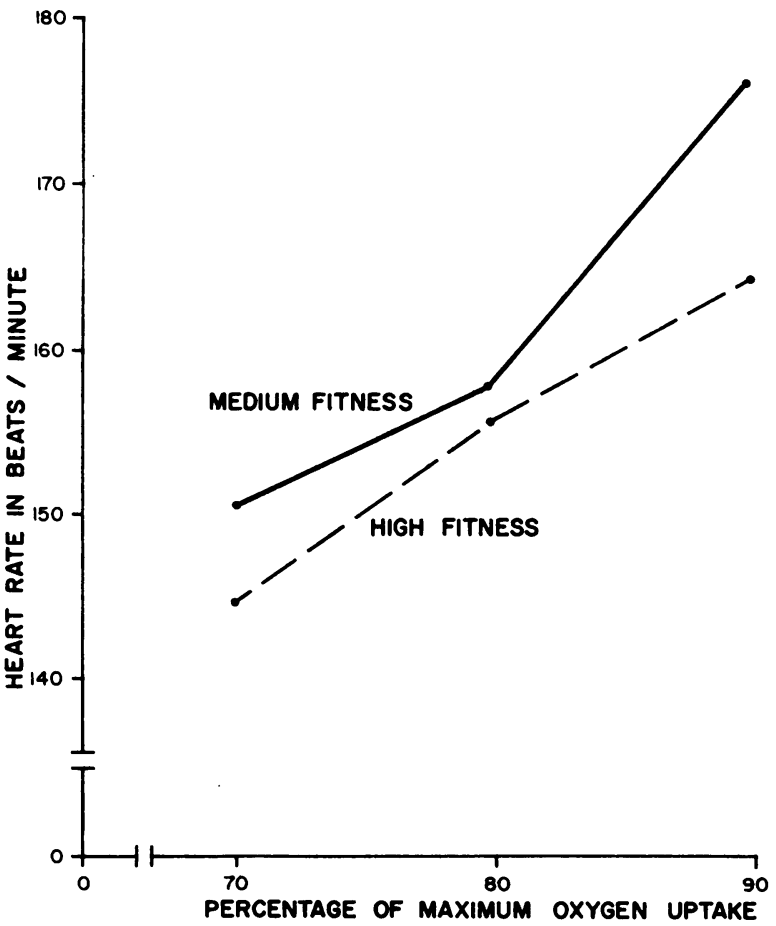

Figure 1. Heart Rates at Submaximal Relative Workloads in Subjects of High and Medium Fitness.

Finally, a completely randomised design analysis of variance was run on the heart rate/min at which $\mathrm{VO}_{2}$ max was attained in the 2 fitness groups. This analysis resulted in a statistically significant $F$ ratio of 5.15. The two means were 181.5 and 172.9 beats $/ \mathrm{min}$ for the medium and high fitness groups respectively. 


\section{Discussion}

The mean $\mathrm{VO}_{2}$ max of the high fitness group of 57 $\mathrm{ml} / \mathrm{kg} \times \min$ is well below the mean $\mathrm{VO}_{2}$ max of 71 $\mathrm{ml} / \mathrm{kg} \times \mathrm{min}$ for 6 marathon runners reported by Costill and Fox (5). However, all six subjects were marathon runners of national ranking whereas only one subject in this study, Jack Mahurin who finished 12th in the 1973 Boston Marathon, was a leading athlete. Moreover, Costill and Fox's data was a result of treadmill workloads and it has been demonstrated recently that $\mathrm{VO}_{2}$ max values are 10.2 to $11.2 \%$ lower on the bicycle ergometer than on the treadmill (10).

The mean heart rates at which $\mathrm{VO}_{2}$ max was attained were 182 and 173 beats/min for the medium and high fitness groups respectively. However, it is relevant to note that these were not maximum heart rates since Karlsson et al. (8) have observed that this parameter is still capable of increasing even though the oxygen uptake curve has levelled off.

Figure 1 portrays the well known Linear relationship between $\mathrm{VO}_{2}$ and heart rate at submaximal workloads. Accordingly the 3 heart rate means of 148,157 and 170 beats $/ \mathrm{min}$ at $70 \%, 80 \%$, and $90 \% \mathrm{VO}_{2}$ max for the combined fitness levels were all statistically different from one another at the .05 level. Figure 1 also demonstrates that the high fitness group experienced lower heart rates at each of the three submaximal relative workloads. However, the overall difference between the fitness levels was not statistically significant. A similar conclusion was reached by Eckblom (6) when evaluating the effect of a 22 week training programme on the heart rate at workloads which elicited $10 \%, 20 \%, 30 \%, 40 \%$, $50 \%$, and $60 \%$ of $\mathrm{VO}_{2}$ max. Bock et al. (4) were probably the first investigators to show that trained persons have a lower heart rate than untrained persons at absolute submaximal workloads due to their larger stroke volume. This has been confirmed by subsequent research $(3,11,12,13)$. It is therefore relevant to note that differences in heart rate, albeit statistically insignificant, still existed between the two fitness levels in this study when all subjects worked at submaximal relative workloads. In such circumstances differences would be smaller than with absolute workloads. The presence of a significant interaction between the two fitness levels for the heart rate at the $90 \% \mathrm{VO}_{2}$ max workload indicates that the difference between the two groups was significantly greater at this highest workload. This is depicted well in Figure 1. A similar trend has been noted when comparing athletes with sedentary people at absolute workloads $(7,12)$ and is no doubt due to the greater cardiac stroke volume of the former.

\section{Acknowledgements}

The computer time for this project was supported by the facilities of the Computer Science Centre of the University of Maryland.

The authors wish to thank J. Mahurin who assisted in the collection of the data. Appreciation is also extended to the 16 subjects.

\section{REFERENCES}

1. Åstrand, P. O., and Rhyming, I. 1954. "A nomogram for calculation of aerobic capacity (physical fitness) from pulse rate during submaximal work." J.Appl.Physiol., 7: 218-221.

2. Åstrand, P. O., and Saltin, B. 1961. "Oxygen uptake during the first minutes of heavy muscular exercise." J.Appl.Physiol., 16: 971-976.

3. Bevegard, S., Holmgren, A., and Jonsson, B. 1963. "Circulatory studies in well trained athletes at rest and during heavy exercise, with special reference to stroke volume and the influence of body position." Acta.Physiol.Scand., 57: 26-50.

4. Bock, A. V., Vancaulaert, C., Dill, D. B., Folling, A., and Hurxthal, L. M. 1928. "Studies in muscular activity III Dynamical changes occurring in man at work." J.Physiol., (London). 66: 136-161.

5. Costill, D. L. and Fox, E. L. 1969. "Energetics of marathon running." Med.Sci.Sports., 1: 81-86.

6. Ekblom, B. 1970. "Effect of physical training on circulation during prolonged severe exercise." Acta Physiol.Scand.., 78: 145-158.

7. Hermansen, L. and Andersen, K. L. 1965. "Aerobic work capacity in young Norwegian men and women." J.Appl.Physiol., 20: 425-431. 
8. Karlsson, J., Åstrand, P. O. and Ekblom, B. 1967. "Training of the oxygen transport system in man." J.Appl.Physiol. 22: 1061-1065.

9. Kearney, J. T., and Stull, G. A. 1971. "A fortran program for the reduction of open-circuit data." Res.Quart., 42: 223-228.

10. McArdle, W. D., Katch, F. I. and Pechar, G. S. 1973. “Comparison of continuous and discontinuous treadmill and bicycle tests for $\mathrm{VO}_{2}$ max." Med.Sci.Sports., 5: 156-160.

11. Musshoff, K., Reindell, H. and Klepzig, H. 1959. "Stroke volume, arteriovenous difference, cardiac output and physical working capacity and their relationship to heart volume." Acta.Cardiol., 14: 427-452.

12. Rowell, L. B., Taylor, H. L., and Wang, Y. 1964. "Limitations to prediction of maximal oxygen intake." J.Appl.Physiol., 19: 919-927.

13. Wang, Y., Shepherd, J. T., Marshall, R. J., Rowell, L. B., and Taylor, H. L. 1961. “Cardiac response to exercise in unconditioned young men and in athletes." Circulation., 24: 1064. 
English and foreign language sources. Published monthly since 1971, and at present includes an average of 85 references per month. The subscription rate is $\mathbf{E 6 . 5 0}$ per annum (pro rata for mailing by air).

SPORTS DOCUMENTATION MONTHLY BULLETIN (formerly Sports Information Monthly Bulletin) lists relevant articles from periodicals. Published monthly since January 1971, and at present includes an average of 375 references per month. The subscription rate is $\mathbf{£ 6 . 5 0}$ per annum (pro rata for mailing by air).

Publications available free of charge are the National Documentation Centre's 'LIST OF PERIODICAL HOLDINGS' and 'LIST OF ABSTRACT JOURNAL HOLDINGS'

The Centre also offers:-

(a) AN ENQUIRY SERVICE, providing on request,

(i) existing lists of references on particular subjects, or

(ii) a list of relevant bibliographic sources.

A charge is made for the lists, which are supplied in the form of photocopies.

(b) A PHOTOCOPY SERVICE. Photocopies are provided in accordance with the provisions of the Copyright Act, 1956, at 4p per exposure, postage and packing extra.

(c) A TRANSLATIONS SERVICE. Translations, at standard fees, may be requested through the Centre.

\section{INTERNATIONAL RELATIONS}

The Centre has very good contacts with documentation and information centres interested in sport and physical recreation in a number of other countries.

\section{FUTURE DEVELOPMENTS}

Plans for the future include establishment of a collection of relevant theses and dissertations; the compilation, in collaboration with other agencies, of registers of current research; and, the development of an education and training programme on the documentation of sport, physical education and recreation.

The Centre hopes to introduce computer assisted techniques for production of its publications and for its enquiry service, at the same time building up a machine-held data base on all aspects of its own fields of interest.

\section{ERRATA}

Mr. R. T. Withers has requested that the following errors be pointed out in his article that appeared in the last issue, Vol. 9 No. 4. Heart rates at submaximal relative workloads in subjects of high and medium fitness. R. T. Withers and R. W. Has/am.

The author wishes to stress that the following errors were not in the original manuscript:

Abstract p. 187

1st paragraph line 1 -

2nd paragraph line 2 -

2nd paragraph line 3 -

2nd paragraph line 6 -

Introduction p. 187

Line 7 to read:

Method p. 187

1st paragraph line 8 to read:

2nd paragraph line 2 to read:

2nd paragraph line 10 to read:

2nd paragraph line 12 to read:

2nd paragraph line 25 to read:

3rd paragraph line 7 to read:

Results p. 188

2nd paragraph line 2 to read:

Discussion p. 189

1st paragraph line 1 to read: 1st paragraph line 2 to read:

2nd paragraph line 2 to read: 3rd paragraph line 1 to read:

3rd paragraph line 3 to read:

References p. 189

Number 1: each $\mathrm{VO}_{2}$ max to be preceded by $\bar{x}$ read 155.2 beats/min in lieu of 155 beats $/ \mathrm{min}$. read 161.4 beats $/ \mathrm{min}$ in lieu of 161 beats $/ \mathrm{min}$.

read 172.9 beats $/ \mathrm{min}$ in lieu of 173 beats $/ \mathrm{min}$ and $181.5 \mathrm{beats} / \mathrm{min}$ in lieu of $182 \mathrm{beats} / \mathrm{min}$.

"differences at submaximal relative workloads ..."

"of a $1.067 \mathrm{~m}$ length of $3.81 \mathrm{~cm}$..."

"continuous workloads of 147 and 205 watts $(900 \ldots$. ."

"and $\mathrm{VO}_{2}$ max was estimated from the Astrand - Ryhming ..."

"an initial $2 \frac{1}{2} \mathrm{~min}$ warmup at 29.4 watts $1900 \mathrm{kgm} / \mathrm{min}$. .."

"point at which an increase in workload of 29.4 watts $(180 \ldots$. ."

"submaximal workloads were then randomly assigned to ..."

“.. The data were..."

56.9 in lieu of 57.

71.4 in lieu of 71.

181.5 and 172.9 in lieu of 182 and 173.

linear in lieu of Linear

147.9, 156.9 and 170.1 in lieu of 148,157 and 170.

read RYHMING in lieu of RHYMING.

The Editor offers his apologies to the authors errors in proof reading and for making some alterations not approved by the authors. 